\title{
Fabaceae na Floresta Nacional (FLONA) de Assú, semiárido potiguar, nordeste do Brasil
}

\author{
Fabaceae at National Forest (FLONA) of Assú, potiguar semiarid, Brazilian northeastern
}

\author{
Louise Duarte Matias de Amorim ${ }^{1}$, Leandro de Oliveira Furtado de Sousa ${ }^{2}$, Francisco Fabio Mesquita Oliveira ${ }^{3}$, \\ Ramiro Gustavo Valera Camacho ${ }^{1}$ \& José Iranildo Miranda de Melo ${ }^{4,5}$
}

\begin{abstract}
Resumo
Fabaceae é a família mais diversa na flora do Brasil, inclusive na Caatinga, principal região natural do nordeste brasileiro. Este trabalho consiste no estudo taxonômico da família Fabaceae na Floresta Nacional (FLONA) de Assú, município de Assú, estado do Rio Grande do Norte, Brasil. Foram registradas 37 espécies distribuídas em 22 gêneros e 3 subfamílias: Caesalpinioideae (07 spp.), Mimosoideae (11 spp.) e Papilionoideae (19 spp.), das quais: Poincianella bracteosa, Mimosa camporum, Mimosa sensitiva, Galactia jussiaeana, Stylosanthes humilis e Vigna peduncularis representam novos registros para a flora do Estado. São apresentadas chaves para a separação das espécies, comentários sobre a taxonomia, dados de distribuição geográfica, floração e frutificação, além de ilustrações para as espécies.
\end{abstract}

Palavras-chave: Brasil, Caatinga, florística, Leguminosae, taxonomia.

\begin{abstract}
Fabaceae is the most diverse family in the flora of Brazil, including the Caatinga vegetation, the main natural region of the Brazilian Northeastern. This work consists in a taxonomic study of the family Fabaceae at the National Forest (FLONA) of Assú, Assú municipality, Rio Grande do Norte State, Brazil. Thirty seven species in twenty two genera and three subfamilies were recorded: Caesalpinioideae (07 spp.), Mimosoideae (11 spp.) and Papilionoideae (19 spp.), which Poincianella bracteosa, Mimosa camporum, Mimosa sensitiva, Galactia jussiaeana, Stylosanthes humilis and Vigna peduncularis representing new occurrences to the flora of the state. Keys for identification of its species, comments on the taxonomy, geographical distribution and flowering and fructification data, as well as illustrations for the species are presented.
\end{abstract}

Key words: Brazil, Caatinga, floristics, Leguminosae, taxonomy.

\section{Introdução}

A Caatinga é a mais importante região natural do Nordeste brasileiro, ocupando aproximadamente $11 \%$ do território nacional, com um enorme potencial para conservação de serviços ambientais, uso sustentável de recursos e bioprospecção (Brasil 2013). Sua biodiversidade, entretanto, tem sido progressivamente perdida, seja pela falta de políticas públicas adequadas, seja pela falta do componente ambiental nos planos de desenvolvimento regionais (Silva et al. 2003). Esses e outros motivos têm contribuído para que o bioma seja um dos mais agredidos do Brasil, além de pouco conhecido, estudado e protegido (Abílio 2010).

\footnotetext{
${ }^{1}$ Universidade do Estado do Rio Grande do Norte - UERN, Programa de Pós-graduação em Ciências Naturais - PPGCN, Av. Prof. Antônio Campos s/n, 59625-620, Presidente Costa e Silva, Mossoró, RN, Brasil.

${ }^{2}$ Universidade Federal Rural do Semiárido - UFERSA, Depto. Ciências Vegetais, Av. Francisco Mota 572, 59625-900, Bairro Costa e Silva, Mossoró, RN, Brasil.

${ }^{3}$ Universidade do Estado do Rio Grande do Norte - UERN, Depto. Ciências Biológicas, Av. Prof. Antônio Campos s/n, 59625-620, Presidente Costa e Silva, Mossoró, RN, Brasil.

${ }^{4}$ Universidade Estadual da Paraíba - UEPB, Depto. Biologia, Centro de Ciências Biológicas e da Saúde, Av. das Baraúnas 351, Campus Universitário, Bairro Universitário, 58429-500, Campina Grande, PB, Brasil.

${ }^{5}$ Autor para correspondência: tournefort@gmail.com
} 
As leguminosas (= Fabaceae) compõem um importante grupo de plantas e representam a maior parte da diversidade florística da região Nordeste do Brasil e do Domínio da Caatinga, onde já foram registradas 603 espécies (BFG 2015).

Fabaceae Lindl. pertence à Ordem Fabales (APG III 2009), e está tradicionalmente dividida em três subfamílias: Caesalpinioideae, Mimosoideae e Papilionoideae (Bentham 1865; Polhill et al. 1981), sendo Caesalpinioideae um grupo parafilético do qual se ramificaram as outras duas subfamílias (LPWG 2013). O grupo é a terceira maior família de plantas do mundo, reunindo 36 tribos, 727 gêneros e 19.325 espécies (Lewis et al. 2005) e seus representantes são encontrados em praticamente todas as formações vegetais do planeta, embora o centro de endemismos da família seja a região neotropical (Lavin et al. 2004). No Brasil, é a família mais bem representada com 2.807 espécies agrupadas em 222 gêneros ( 15 endêmicos) abundantes em quase todos os biomas e ecossistemas do país (BFG 2015).

No cenário de desmatamento acelerado e perda de biodiversidade da Caatinga, o Rio Grande do Norte (RN) se destaca, sendo um dos estados brasileiros que menos protege sua biodiversidade (Santos \& Jerônimo 2013). Uma das melhores alternativas na luta pela preservação dos recursos naturais do país é a criação e manutenção de Unidades de Conservação (Brasil 2002). A Floresta Nacional (FLONA) de Assú é uma Unidade de Conservação (UC) de grande expressividade no
Rio Grande do Norte, principalmente por ser a única da esfera federal destinada à proteção da Caatinga no Estado (IDEMA 2013).

Diante do exposto, e da necessidade de ampliar os conhecimentos sobre a flora da Caatinga, em especial para o semiárido potiguar, este trabalho consiste no estudo florísticotaxonômico das Fabaceae na Floresta Nacional (FLONA) de Assú, município de Assú, Rio Grande do Norte, Brasil, e inclui chaves para a identificação de espécies, comentários, ilustrações e imagens de ambientes e espécies, e dados de distribuição geográfica e de fenologia.

\section{Material e Métodos}

Área de estudo

Este estudo foi realizado na Floresta Nacional (FLONA) de Assú, Unidade de Conservação Federal criada pela portaria $n .^{\circ} 245$ de 18/07/2001, com o objetivo de promover o manejo adequado dos recursos naturais da Caatinga (ICMBio 2013). A FLONA apresenta cobertura florestal de Caatinga nativa e ocupa atualmente uma área de 528,25 ha. De acordo com Miranda et al. (2007), está inserida no sudoeste do sítio urbano do município de Assú (0534'20"'S, 36 $\left.54^{\circ} 33^{\prime \prime} \mathrm{W}\right)$, região central do Estado do Rio Grande do Norte, Nordeste do Brasil (Fig. 1).

O município de Assú caracteriza-se por apresentar clima quente e semiárido, com chuvas torrenciais concentradas entre os meses de março e abril e índice pluviométrico variando entre 500 e $800 \mathrm{~mm} / \mathrm{ano}$, embora a irregularidade das chuvas seja uma constante uma vez que se trata de um

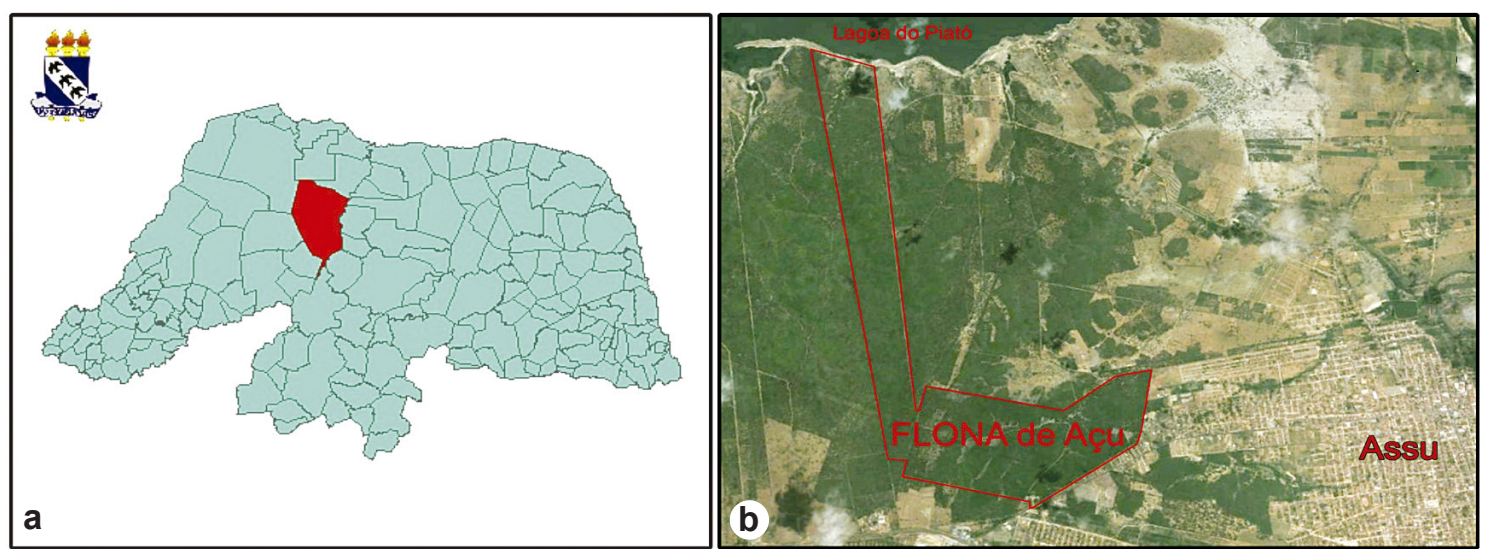

Figura 1 - a. localização do municipio de Assú no estado do Rio Grande do Norte; b. localização da área de estudo, Floresta Nacional (FLONA) de Assú no município.

Figure 1 - a. location of the municipality of Assú in the Rio Grande do Norte state; b. location of the study area, National Forest (FLONA) in the municipality of Assú. 
clima predominantemente semiárido (Brasil 2013). A hidrografia do local é marcada pela riqueza de águas subterrâneas, bem como pelo Rio PiranhasAssú e seus afluentes, lagoas e açudes (Secretaria Municipal de Desenvolvimento e Meio Ambiente de Assú 2001). Do ponto de vista pedológico, predominam na região do vale do Assú, os solos rasos, pedregosos, de origem cristalina e fertilidade de média a alta, embora muito susceptíveis à erosão (Costa 2006). Segundo Lira et al. (2007), a Caatinga da FLONA de Assú apresenta um aspecto fisionômico marcado por uma formação vegetal arbóreo-arbustiva densa, onde predominam as plantas de alto e médio porte (Fig. 2).

\section{Estudos de campo e laboratório}

O processo de coleta e herborização foi baseado em Bridson \& Formann (2004). A coleta de material botânico foi realizada entre Março/2013 e Maio/2014, através de caminhadas aleatórias no interior da área, buscando explorá-la em toda a sua extensão. As coletas se estenderam ao longo do corredor ecológico que se prolonga até a Lagoa do Piató (Fig. 1b). Durante as incursões foram coletados espécimes férteis (flores e/ou frutos) de todos os representantes de Fabaceae associados aos estratos herbáceo e lenhoso da FLONA. Para cada indivíduo amostrado foram registradas as coordenadas geográficas através de GPS (Global Positioning System) utilizadas posteriormente na confecção de mapas que indicam os pontos onde foram observados e coletados os espécimes. Os espécimes foram incorporados ao acervo do herbário Dárdano de Andrade-Lima (MOSS), da Universidade Federal Rural do SemiÁrido (UFERSA).

As análises morfológicas foram feitas com base nos espécimes coletados na área de estudo, utilizando a literatura especializada e a análise comparativa de espécimes provenientes do Herbário Dárdano de Andrade-Lima (MOSS). As estruturas

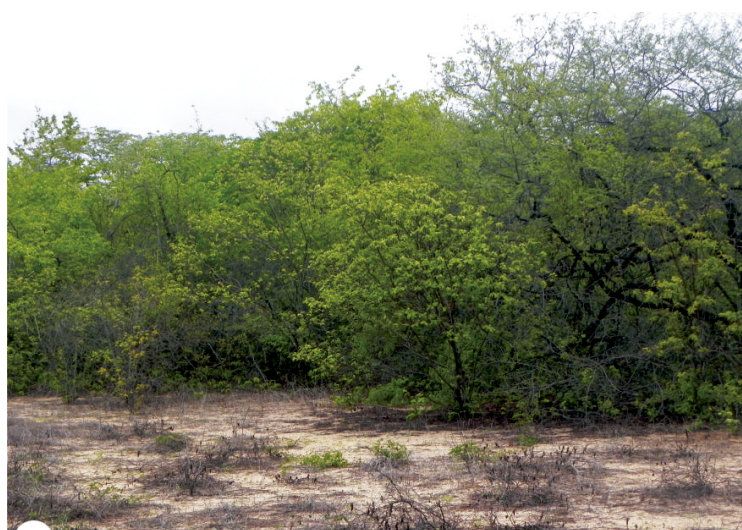

a

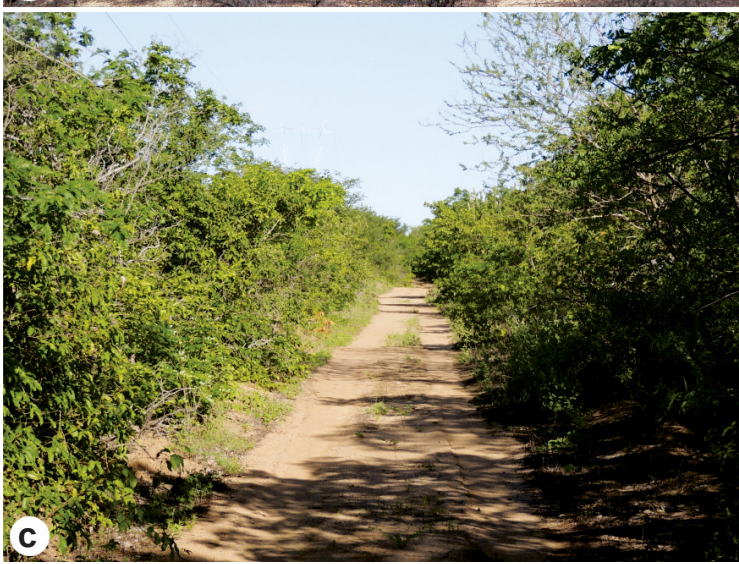

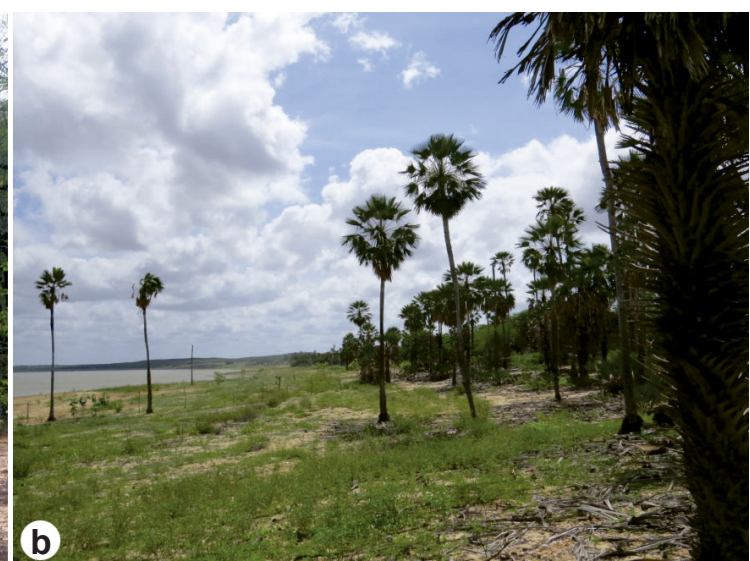

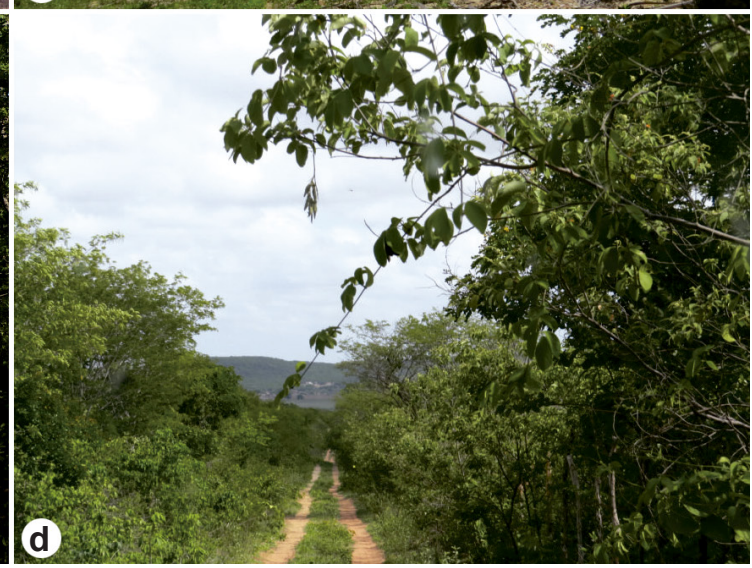

Figura 2 - Fisionomias da vegetação de Caatinga da Floresta Nacional (FLONA) de Assú, Assú, Rio Grande do Norte, Brasil - a. estrato arbustivo-arbóreo; b. estrato herbáceo; c. trilha principal da área de estudo; d. corredor ecológico. Figure 2 - Physiognomies of the Caatinga vegetation at the National Forest (FLONA) of Assú, Assú, Rio Grande do Norte state, Brazil - a. shrub-tree stratum; b. herbaceous stratum; c. main trail of the study area; d. ecological corridor. 
morfológicas foram caracterizadas com base na terminologia empregada por Hickey (1973), Radford et al. (1974), Rizzini (1977), Payne (1978) e Harris \& Harris (2001). Foram elaboradas pranchas contendo imagens digitalizadas de espécies e ambientes e pranchas com estampas do hábito e outros importantes aspectos das espécies registradas neste estudo. Também são apresentados comentários taxonômicos baseados em caracteres morfológicos, relação de material examinado, dados de distribuição geográfica, ambientes preferenciais, floração e frutificação das espécies. Para a confecção do mapa da área de estudo foi utilizado o software Arcview 10.1.

\section{Resultados e Discussão}

$\mathrm{O}$ estudo taxonômico de Fabaceae na Floresta Nacional (FLONA) de Assú resultou no reconhecimento de 37 espécies pertencentes a 22 gêneros nas três subfamílias (Tab. 1): Caesalpinioideae (4 gêneros, 7 espécies), Mimosoideae (6 gêneros, 11 espécies) e Papilionoideae (12 gêneros, 19 espécies), sendo esta última a mais diversificada na área de estudo possivelmente por possuir o mais elevado número de espécies na família como um todo. Mimosa L. é o gênero mais representativo, com seis espécies, seguido por Chamaecrista Moench, Macroptilium (Benth.) Urb. e Stylosanthes Sw., com três espécies cada; Bauhinia L., Centrosema (DC.) Benth., Indigofera L. e Zornia J.F. Gmel, apresentaram duas espécies cada. Os demais gêneros foram representados por apenas uma espécie cada: Libidibia (DC.) Schltdl., Poincianella Britton \& Rose, Anadenanthera Speg., Enterolobium Mart.,
Piptadenia Benth., Pityrocarpa (Benth.) Britton \& Rose, Neptunia Lour., Amburana Schwacke \& Taub., Aeschynomene L., Canavalia DC., Galactia P. Browne, Tephrosia Pers., Trischidium Tul. e Vigna Savi.

Dentre as espécies encontradas, seis constituem novos registros para a flora do Rio Grande do Norte: Poincianella bracteosa, Mimosa camporum, Mimosa sensitiva, Galactia jussiaeana, Stylosanthes humilis e Vigna peduncularis, um número expressivo de novos registros considerando que Fabaceae é uma família amplamente conhecida embora a flora da caatinga, em especial a do Rio Grande do Norte seja ainda pouco estudada do ponto de vista florístico-taxonômico.

Os resultados também mostram uma expressiva riqueza de tipos de hábitos, também apontada por Queiroz (2009) para as espécies de Fabaceae da Caatinga. Na área, foram registradas espécies herbáceas $(37,8 \%)$, arbustivas ou subarbustivas $(35,1 \%)$, trepadeiras $(8,1 \%)$ e arbóreas $(19,9 \%)$. A preferência das espécies por solos arenosos também pode ser observada apesar da diversidade de ambientes e tipos de solos encontrados na FLONA de Assú. Este estudo também revelou a ocorrência, na área de estudo, de nove espécies endêmicas da flora brasileira: Bauhinia subclavata Benth., Libidibia ferrea (Mart. ex Tul.) L.P. Queiroz var. ferrea, P. bracteosa, Indigofera blanchetiana Benth., Indigofera microcarpa Desv., Trischidium molle, Mimosa caesalpiniifolia Benth., Mimosa modesta Mart. var. modesta e Piptadenia stipulacea (Benth.) Ducke.

\section{Chave para separação das espécies de Caesalpinioideae na FLONA de Assú}

1. Erva; botões florais ovóides; frutos com valvas membranáceas.........................................................2

1'. Árvores ou arbustos; botões florais não ovóides; frutos com valvas lenhosas .................................... 4

2. Estípulas de 7-8 mm de comprimento, adpressas ao ramos; folha com um par de folíolos; sépala de até $4 \mathrm{~mm}$ de comprimento; 5 estames férteis

2'. Estípulas de 2-5 mm de comprimento, não adpressas ao ramos; folha com 2-10 pares de folíolos; sépala de 6,5-11 mm de comprimento; 8-10 estames férteis.

3. Estípulas ovais a lanceoladas; pecíolo $2-4 \mathrm{~mm}$ de comprimento, com nectário extrafloral, 8-10 pares de folíolos de ápice mucronado; flores solitárias, bractéolas-2; estaminódios-2; fruto apiculado Chamaecrista calycioides

3'. Estípulas subuladas; pecíolo $27-35 \mathrm{~mm}$ de comprimento, sem nectário extrafloral; 2 pares de folíolos de ápice obtuso; inflorescência racemosa; bractéolas-3; estaminódios ausentes; fruto não apiculado Chamaecrista hispidula 
4. Folhas lobadas; flores pareadas; sépalas oblongas; pétalas inteiramente brancas; ovário exserto do hipanto.

4'. Folhas pinadas; flores multirramosas; sépalas ovadas; pétala vexilar pintalgada de vermelho-claro; ovário inserido no hipanto

5. Ramos inermes; lâmina dividida por ca. de 1/4 do seu comprimento, lobos arredondados; bractéolas localizadas na base do pedicelo; sépalas não apiculadas; pétalas lineares na ântese; androceu homomórfico; frutos de valvas vilosas. Bauhinia subclavata

5'. Ramos armados; lâmina dividida por ca. de 2/3 do seu comprimento, lobos oblongos; bractéolas localizadas ao longo do pedicelo; sépalas com apículo de ca. $1 \mathrm{~mm}$ de comprimento; pétalas espiraladas na antese; androceu dimórfico; frutos de valvas glabras

Bauhinia pentandra

6. Ramos com muitos tricomas glandulares; pinas e folíolos alternos, venação broquidódroma; brácteas ovais, 6-11 compr. $\times$ 4-8 mm larg.; flores articuladas logo abaixo do hipanto; androceu dimórfico; legume deiscente, compresso, estipitado. Poincianella bracteosa

6'. Ramos sem tricomas glandulares; pinas e folíolos opostos, venação peninérvea; brácteas deltóides, 1,5 compr. $\times$ 0,5 mm larg.; flores articuladas ca. $2 \mathrm{~mm}$ abaixo do hipanto; androceu homomórfico; legume indeiscente, não compresso, séssil. Libidibia ferrea

Bauhinia pentandra Vogel ex Steud., Nom. Bot. Ed. 2,1: 992. 1840.

Fig. 3a

Material examinado: BRASIL. Rio Grande do Norte: Assú, Floresta Nacional de Assú, 25.V.2013, fl. e fr., L.D.M. Amorim 26 (MOSS).

No Brasil, ocorre nos Estados do Ceará, Rio Grande do Norte, Paraíba, Pernambuco, Bahia, Alagoas, Piauí, Sergipe, Minas Gerais, Mato Grosso, Mato Grosso do Sul, Rio de Janeiro e São Paulo (BFG 2015). De acordo com Vaz \& Tozzi (2003), também é comumente encontrada na Bolívia.

Bauhinia pentandra é facilmente reconhecida pelas folhas bilobadas, com lobos divergentes separados até próximo à base. Distingue-se de B. subclavata, com a qual é morfologicamente assemelhada, principalmente pela forma da lâmina foliar e pela disposição das inflorescências, além de apresentar androceu dimórfico. Coletada florida e frutificada em maio.

Bauhinia subclavata Benth. in Mart. Fl. Brasil. 15 (2): 188. 1870.

Material examinado: BRASIL. Rio Grande do Norte: Assú, Floresta Nacional de Assú, 25.V.2013, fl. e fr., L.D.M. Amorim 25(MOSS).

Esta espécie é pouco conhecida no Brasil, restringindo-se ao Cerrado e à Caatinga. Ocorre nos Estados da Bahia, Ceará, Maranhão, Paraíba, Piauí e Rio Grande do Norte, sendo encontrada em florestas estacional decidual e semidecidual (BFG 2015). Na área de estudo, foi encontrada sobre solo arenoso.

Bauhinia subclavata pode ser reconhecida pelas folhas orbiculares quase tão longas quanto largas, discretamente lobadas, e divergentes entre si. A presença de botões 5-costados no ápice também é uma importante característica distintiva. Coletada com flores e frutos em maio.

Chamaecrista calycioides (Collad.) Greene, Pittonia 4: 32. 1899.

Fig. 3b

Material examinado: BRASIL. Rio Grande do Norte: Assú, Floresta Nacional de Assú, 03.V.2014, fl. e fr., L.D.M. Amorim 76 (MOSS).

Ocorre no México, Guiana Francesa, Venezuela, Paraguai, Argentina e, no Brasil, (Irwin \& Barneby 1982), onde se distribui nos Estados do Pará, Roraima, Bahia, Goiás, São Paulo e Rio Grande do Norte (BFG 2015).

Distingue-se facilmente das demais espécies de Chamaecrista registradas na área de estudo por apresentar 8-10 pares de folíolos, pedicelo e estípite frutífero curtos, além de possuir nectários extraflorais. Chamaecrista calycioides é uma espécie comum na FLONA de Assú, podendo ser encontrada em praticamente toda a extensão da trilha principal da área. Coletada florida e frutificada em maio.

Chamaecrista hispidula (Vahl) H.S. Irwin \& Barneby, Mem.New York Bot. Gard. 35(2): 661. 1982.

Material examinado: BRASIL. Rio Grande do Norte: Assú, Floresta Nacional de Assú, 06.V.2014, fl. e fr., L.D.M. Amorim 91 (MOSS).

No Brasil, ocorre em praticamente todas as regiões, com exceção da região Sul, e no Nordeste ocorre em todos os Estados. Segundo Souza \& 
Tabela 1 - Espécies de Fabaceae registradas na área de estudo, Floresta Nacional (FLONA) de Assú, Assú, Rio Grande do Norte, Brasil, com respectivas subfamílias e tipos de hábitos.

Table 1 - Fabaceae species recorded in the study area, National Forest (FLONA) of Assú, Assú, Rio Grande do Norte state, Brazil, with their respective subfamilies and types of habits.

\begin{tabular}{|c|c|c|}
\hline Subfamília & Espécie & Hábito \\
\hline \multirow[t]{7}{*}{ Caesalpinioideae } & Bauhinia pentandra (Bong.) D.Vogel ex Steud. & Subarbusto \\
\hline & Bauhinia subclavata Benth. & Subarbusto \\
\hline & Chamaecrista calycioides (Collad.) Greene & Erva \\
\hline & Chamaecrista hispidula (Vahl) H.S.Irwin \& Barneby & Erva \\
\hline & Chamaecrista rotundifolia (Pers.) Greene var. rotundifolia & Erva \\
\hline & Libidibia ferrea (Mart. ex Tul.) L.P. Queiroz var. ferrea & Árvore \\
\hline & Poincianella bracteosa (Tul.) L.P. Queiroz & Arbusto \\
\hline \multirow[t]{11}{*}{ Mimosoideae } & Anadenanthera colubrina (Vell.) Brenan & Árvore \\
\hline & Enterolobium contortisiliquum (Vell.) Morong. & Árvore \\
\hline & Mimosa caesalpiniifolia Benth. & Árvore \\
\hline & Mimosa camporum Benth. & Erva, ereta \\
\hline & Mimosa modesta Mart. var. modesta. & Erva \\
\hline & Mimosa quadrivalvis var. leptocarpa (DC.) Barneby & Subarbusto \\
\hline & Mimosa sensitiva $\mathrm{L}$. & Subarbusto \\
\hline & Mimosa tenuiflora (Willd.) Poir. & Arbusto \\
\hline & Piptadenia stipulacea (Benth.) Ducke & Árvore \\
\hline & Pityrocarpa moniliformis (Benth.) Luckow\& Jobson & Árvore \\
\hline & Neptunia plena (L.) Benth. & Subarbusto \\
\hline \multirow[t]{19}{*}{ Papilionoideae } & Amburana cearensis (Allemão) A.C. Sm. & Árvore \\
\hline & Aeschynomene viscidula Michx. & Erva \\
\hline & Canavalia brasiliensis Mart. ex Benth. & Trepadeira \\
\hline & Centrosema brasilianum (L.) Benth. & Trepadeira \\
\hline & Centrosema rotundifolium Mart. ex Benth. & Erva, prostrada \\
\hline & Galactia jussiaeana Kunth & Subarbusto \\
\hline & Indigofera blanchetiana Benth. & Subarbusto \\
\hline & Indigofera microcarpa Desv. & Erva, prostrada \\
\hline & Macroptilium atropurpureum (Sessé \& Moc. ex DC.) Urb. & Erva \\
\hline & Macroptilium lathyroides (L.) Urb. & Erva \\
\hline & Macroptilium martii (Benth.) Maréchal \& Baude & Erva \\
\hline & Stylosanthes angustifolia Vogel & Erva \\
\hline & Stylosanthes humilis Kunth & Erva \\
\hline & Stylosanthes scabra Vogel & Subarbusto \\
\hline & Tephrosia purpurea (L.) Pers. subsp. purpurea & Subarbusto \\
\hline & Trischidium molle (Benth.) H.F. Ireland & Arbusto \\
\hline & Vigna peduncularis(Kunth) Fawc. \& Rendle & Trepadeira \\
\hline & Zornia brasiliensis Vogel & Subarbusto \\
\hline & Zornia gemella(Willd.) Vogel & Erva \\
\hline
\end{tabular}



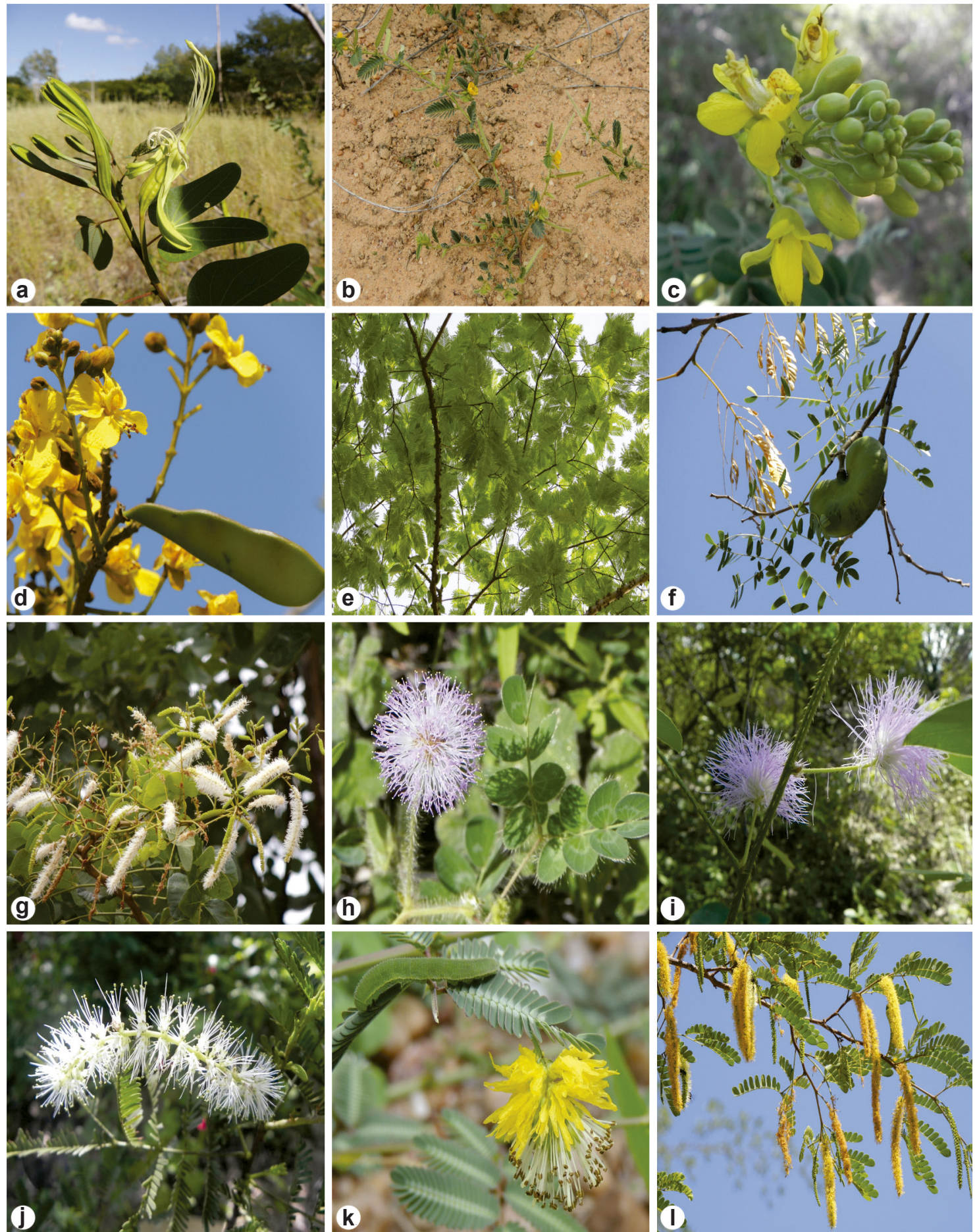

Figura 3 - Diversidade morfológica de espécies de Fabaceae da Floresta Nacional (FLONA) de Assú, Assú, Rio Grande do Norte, Brasil - a. Bauhinia pentandra; b. Chamaecrista calycioides; c. Libidibia ferrea; d. Poincianella bracteosa; e. Anadenanthera colubrina; f. Enterolobium contortisiliquum; g. Mimosa caesalpiniifolia; h. Mimosa modesta; i. Mimosa sensitiva; j. Mimosa tenuiflora; k. Neptunia plena; 1. Pityrocarpa moniliformis; Fonte: Louise Amorim (b,c,h,i,j), Leandro Furtado (a,d,e,f,g,k,l).

Figure 3-Morphological diversity of its species of Fabaceae at the National Forest(FLONA) of Assú, Assú, Rio Grande do Norte state, Brazil -a. Bauhinia pentandra; b. Chamaecrista calycioides; c. Libidibia ferrea; d. Poincianella bracteosa; $;$ e. Anadenanthera colubrina; ;. Enterolobium contortisiliquum; $\mathrm{g}$. Mimosa caesalpinïfolia; h. Mimosa modesta; i. Mimosa sensitiva; ;. Mimosa tenuiflora; k. Neptunia plena; 1. Pityrocarpa moniliformis; Source: Louise Amorim (b,c,h,i,j), Leandro Furtado (a,d,e,f,g,k,l). 
BFG (2015), é um elemento comum na Floresta Amazônica, Cerrado, Mata Atlântica e Caatinga, comportando-se como espécie invasora. $\mathrm{Na}$ área de estudo, foi encontrada às margens da Lagoa do Piató.

Chamaecrista hispidula pode ser reconhecida, principalmente, pela presença de dois pares de folíolos. Coletada florida e frutificada em maio.

Chamaecrista rotundifolia (Pers.) Greene, Pittonia 4: 31. 1899.

Material examinado: BRASIL. Rio Grande do Norte: Assú, Floresta Nacional de Assú, 03.V.2014, fl. e fr., L.D.M. Amorim 71 (MOSS).

Esta espécie é amplamente difundida na América Central e América do Sul (Irwin \& Barneby 1982). No Brasil, pode ser encontrada em todas as regiões e Estados do Nordeste, tendo sido recentemente citada para o Rio Grande do Norte (Queiroz \& Loiola 2009). Está associada a locais abertos, iluminados, beira de estradas e ambientes perturbados com solos arenosos e pedregosos (Fernandes \& Garcia 2008). Encontrada florida e frutificada em maio.

Caracteriza-se morfologicamente por apresentar um único par de folíolos e pelos ramos prostrados. Além disso, quando comparada às espécies congêneres registradas nesse trabalho, apresenta flores menores e estames em número menor que as mesmas.

Libidibia ferrea (Mart. ex Tul.) L.P. Queiroz var. ferrea, Legum. Caatinga: 130. $2009 . \quad$ Fig. 3c Material examinado: BRASIL. Rio Grande do Norte: Assú, Floresta Nacional de Assú, 16. III.2013, fl. e fr., L.D.M. Amorim 09 (MOSS).
Esta espécie é endêmica do Brasil, ocorrendo naturalmente no Nordeste e Sudeste do país (com exceção do estado de São Paulo) em áreas de Caatinga, Cerrado e Mata Atlântica (Lewis 2014a).

Libidibia ferrea é uma espécie típica da Caatinga do nordeste brasileiro (Queiroz 2009). Diferencia-se das demais Caesalpinioideae registradas nesse estudo por apresentar hábito arbóreo com aproximadamente 5,5 $\mathrm{m}$ de altura. Diferenciase das espécies de Bauhinia e Chamaecrista, principalmente, pela deciduidade de suas estípulas, presença de brácteas e pelas flores articuladas. Coletada florida e frutificada em março.

Poincianella bracteosa (Tul.) L.P. Queiroz, Legum. Caatinga: 122. $2009 . \quad$ Fig. 3d Material examinado: BRASIL. Rio Grande do Norte: Assú, Floresta Nacional de Assú, 16.III.2013, fl. e fr., L.D.M. Amorim 07(MOSS); Ibidem, 25.V.2013, fl., L.D.M. Amorim 23 (MOSS).

Poincianella bracteosa é endêmica do Brasil, típica de formações secas, ocorrendo principalmente na Caatinga arbórea e cerrado (Queiroz 2009). De acordo com BFG (2015), no Brasil se distribui nas regiões Norte (Tocantins), Centro-Oeste (Goiás, Mato Grosso) e Nordeste (Ceará, Maranhão, Paraíba, Piauí) e para o Rio Grande do Norte está sendo referida pela primeira vez neste trabalho.

Esta espécie é morfologicamente relacionada à $L$. ferrea, com a qual compartilha pontuações lenticelares na casca, estípulas precocemente decíduas e pelas panículas terminais. Caracterizase, principalmente, por apresentar brácteas grandes e largamente ovais. Encontrada florida em março e maio e frutificada em março.

\section{Chave para separação das espécies de Mimosoideae na FLONA de Assú}

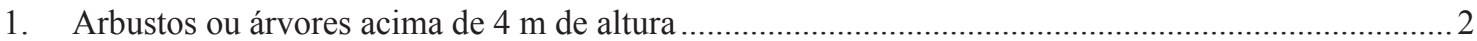

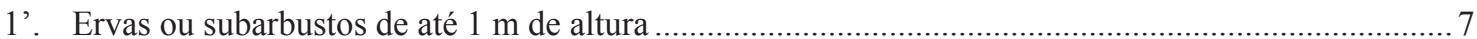

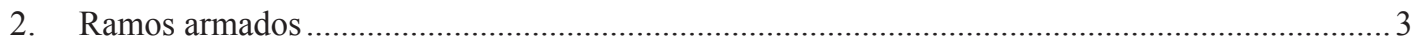

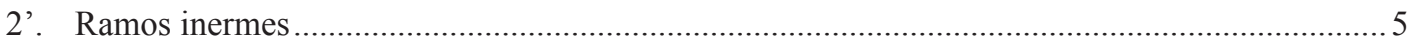

3. Presença de pontuações glandulares negras; até 4 pares de folíolos estes irregularmente obovais, de base oblíqua; espiga fasciculada; ovário séssil ............. Mimosa caesalpiniifolia

3'. Ausência de pontuações glandulares; folíolos numerosos $\geq 17 \leq 39$; oblongo-lineares, de base assimétrica; espiga ou glomérulo, não fasciculada; ovário estipitado .

4. Ramos estriados, acinzentados; foliólulos 33-39 pares, nectários extraflorais crateriformes; sem espículas e parafilídios interfoliolares; inflorescência amarela; flores pentâmeras; estames 10 ............................................................ Piptadenia stipulacea

4'. Ramos não estriados, nigrescentes; foliólulos 17-24 pares, sem nectários extraflorais; espículas e parafilídios interfoliolares presentes; inflorescência branca; flores tetrâmeras; estames 8 Mimosa tenuiflora 
5. Plantas de até 5,5 m de altura; ramos não estriados; flores diplostêmones; estames 10, dialistêmones; ovário estipitado, exserto da flor.

5'. Plantas acima de $8 \mathrm{~m}$ de altura; ramos estriados; flores polistêmones; estames numerosos $(>10)$, gamostêmones; ovário séssil, não exserto da flor ..... Enterolobium contortisiliquum

6. Caule com projeções cônicas; 18-22 pares de pinas, ápice do folíolo agudo; inflorescência do tipo glomérulo; cálice glabro; estames isodínamos.. Anadenanthera colubrina

6'. Caule sem projeções cônicas; 3-4 pares de pinas, ápice do pecíolo obtuso; inflorescência do tipo espiga, pêndula; cálice pubescente; estames heterodínamos

Pityrocarpa moniliformis

7. Ramos armados; frutos sésseis. 8

7'. Ramos inermes; frutos estipitados 10

8. Folhas com 2-3 pares de pinas; foliólulos oblongo-lineares de base assimetricamente truncada; flores róseas.

8'. Folhas com 1 par de pina; foliólulos elípticos de base assimetricamente cordada; flores lilases. Mimosa sensitiva

9. Subarbustos, ramos 4-costados, acúleos numerosos; foliólulos 2-3 nérvios; flores pentâmeras; lacínias da corola levemente encurvadas; anisostêmone-6. Mimosa quadrivalvis

9'. Ervas, ramos não costados, acúleos esparsos; foliólulos 5 nérvios; flores tetrâmeras; lacínias da corola retas; diplostêmone-8 . Mimosa camporum

10. Ervas, ramos sem pontuações glandulares; folhas com 1 par de pinas, com estipelas; sem nectários extraflorais; foliólulo de margem ciliada; flores tetrâmeras, isostêmones. Mimosa modesta

10'. Subarbustos, ramos com pontuações glandulares nigrescentes; folhas com 3 pares de pinas, sem estipelas; nectários extraflorais presentes; foliólulo de margem glabra; flores pentâmeras, diplostêmones.

Neptunia plena

Anadenanthera colubrina (Vell.) Brenan, Kew Bull. 1955: 182.

Material examinado: BRASIL. Rio Grande do Norte: Assú, Floresta Nacional de Assú, 16.III.2013, L.D.M. Amorim 04 (MOSS).

Material adicional examinado: BRASIL. Rio Grande do Norte: Mossoró, Serra de Mossoró, 27.VII.1972, fl. e fr., O.F. Oliveira 51 (MOSS).

Anadenanthera colubrina ocorre desde o Maranhão até Minas Gerais, em áreas de Caatinga e florestas estacionais (Weber et al. 2011). De acordo com Queiroz (2009), embora esta espécie não seja endêmica da Caatinga é bem adaptada a essa região, sendo uma das representantes lenhosas típicas do bioma.

Esta espécie pode ser reconhecida por apresentar projeções cônicas na epiderme e pela casca fortemente avermelhada. Os ramos possuem pontuações lenticelares e numerosos pares de folíolos. Os caracteres reprodutivos foram descritos com base em um espécime coletado no Distrito de Baraúna, hoje município de mesmo nome (Rio Grande do Norte).
Enterolobium contortisiliquum (Vell.) Morong, Ann. New York Acad. Sci. 7: 102. $1893 . \quad$ Fig. 3f Material examinado: BRASIL. Rio Grande do Norte: Assú, Floresta Nacional de Assú, 03.V.2014, L.D.M. Amorim 83 (MOSS).

Material adicional examinado: BRASIL. Rio Grande do Norte: Coronel João Pessoa, Serra de São José, 14.X.1980, fl. e fr., O.F. Oliveira et al. 1428 (MOSS).

No Brasil, estende-se do Ceará ao Rio Grande do Sul, além de alguns Estados da região CentroOeste. A espécie é comum em áreas de Cerrado e Mata Atlântica, em floresta ciliar, estacional semidecidual e ombrófila (BFG 2015). Na área de estudo, foi encontrada no inicio da trilha principal, sendo representada por apenas um indivíduo.

Assemelha-se morfologicamente a $A$. colubrina principalmente pelo porte e pelos nectários extraflorais discóides. No entanto, pode ser reconhecida pela ausência de projeções cônicas nos ramos e pelo fruto auriculiforme. O espécime não foi encontrado em estágio reprodutivo e, por esta razão, a descrição das estruturas reprodutivas foi baseada em material complementar. 

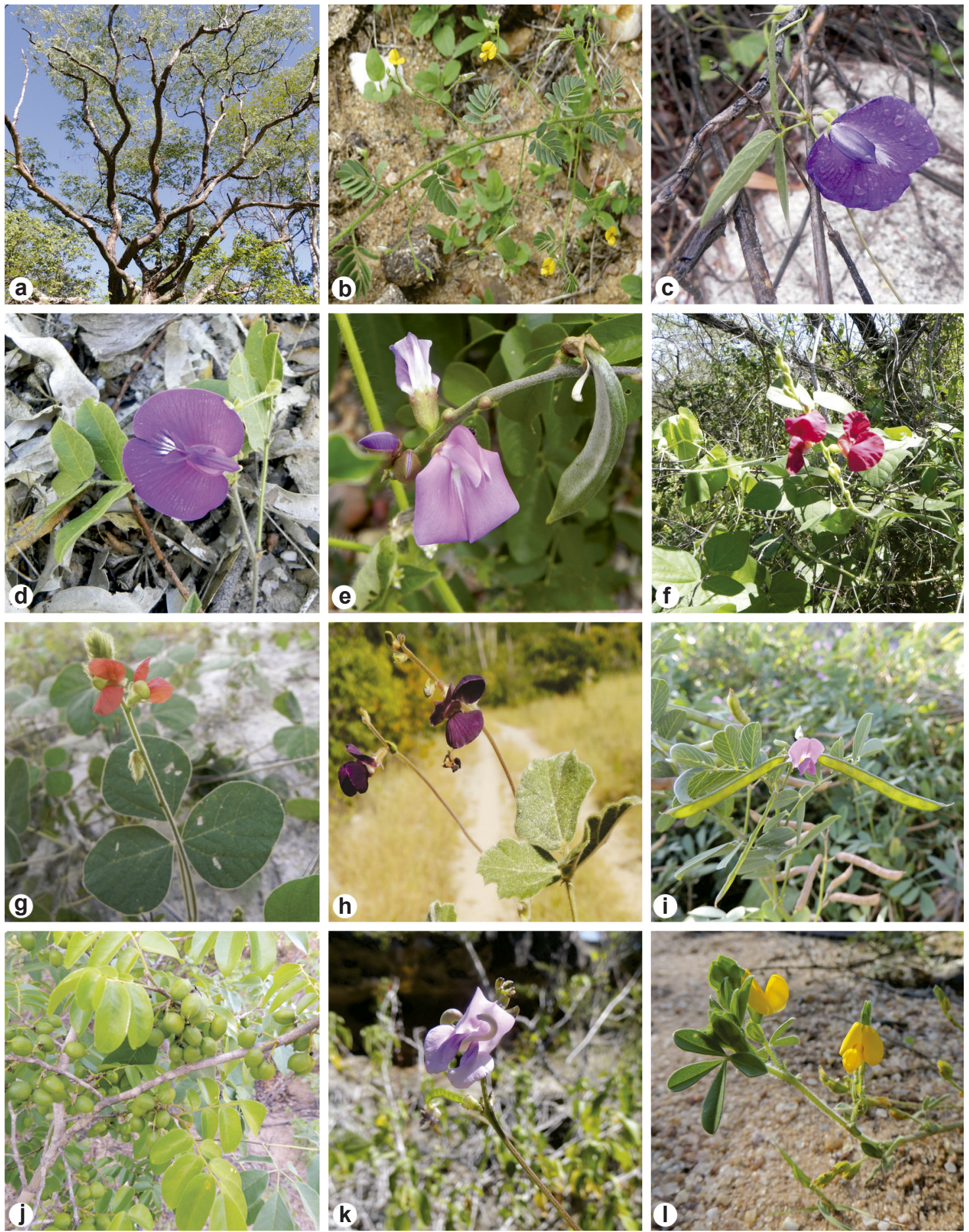

Figura 4 - Diversidade morfológica de espécies de Fabaceae da Floresta Nacional (FLONA) de Assú, Assú, Rio Grande do Norte, Brasil - a. Amburana cearensis; b. Aeschynomene viscidula; c. Centrosema brasilianum; d. Centrosema rotundifolium; e. Canavalia brasiliensis; f. Macroptilium lathyroides; g. Macroptilium martii; h. Macroptilium atropurpureum; i. Tephrosia purpurea; j. Trischidium molle; k. Vigna peduncularis; 1. Zornia brasiliensis. Fonte: Louise Amorim (b-g,j,1); Leandro Furtado (a,h,i,k). Figure 4 - Morphological diversity of its species of Fabaceae at the National Forest (FLONA) of Assú, Assú, Rio Grande do Norte state, Brazil - a. Amburana cearensis; b. Aeschynomene viscidula; c. Centrosema brasilianum; d. Centrosema rotundifolium; e. Canavalia brasiliensis; f. Macroptilium lathyroides; g. Macroptilium martii; h. Macroptilium atropurpureum; i. Tephrosia purpurea; j. Trischidium molle; k. Vigna peduncularis; 1 . Zornia brasiliensis. Source: Louise Amorim (b-g,j,1); Leandro Furtado (a,h,i,k). 
Mimosa caesalpiniifolia Benth., J. Bot. (Hooker) 4: 392. 1842.

Fig. $3 g$

Material examinado: BRASIL. Rio Grande do Norte: Assú, Floresta Nacional de Assú, 06.V.2014, fl., L.D.M. Amorim 92 (MOSS).

Esta espécie é endêmica do Brasil (BFG 2015). Ocorre em Minas Gerais (Sudeste) e em vários Estados da região Nordeste (Carvalho 2007), principalmente em solos arenosos à beira de rios e menos frequentemente em matas ciliares (Queiroz 2009).

Mimosa caesalpiniifolia é uma das plantas mais representativas da fisionomia da Caatinga, diferenciando-se das demais espécies de Mimosoideae registradas nesse trabalho especialmente pela dimensão dos foliólulos ligeiramente obovais embora se aproxime de Mimosa tenuiflora pelo hábito arbóreo. Encontrada florida em maio.

Mimosa camporum Benth., J. Bot. (Hooker) 2: 130. 1840.

Material examinado: BRASIL. Rio Grande do Norte: Assú, Floresta Nacional de Assú, 27.VII.2013, fr., L.D.M. Amorim 57 (MOSS).

Material adicional examinado: BRASIL. Ceará: Iguatú: Reserva Particular do Patrimônio Natural Fazenda Trussu, 15.VI. 2008, fl. e fr., O.F. Oliveira 87 (MOSS).

Mimosa camporum é nativa do Brasil distribuindo-se nas regiões Norte e Nordeste do país, estando associada às vegetações de Cerrado, Floresta Amazônica e Caatinga (BFG 2015). Nesse trabalho constitui um novo registro para o Rio Grande do Norte.

Uma característica marcante e distintiva da espécie é a presença de craspédio multifasciculado. Diferencia-se das demais espécies congêneres registradas nesse trabalho pelo hábito herbáceo, ereto. Encontrada frutificada em julho.

Mimosa candollei R. Grether, Novon 10(1): 34. 2000.

Material examinado: BRASIL. Rio Grande do Norte: Assú, Floresta Nacional de Assú, 03.V.2014, fl. e fr., L.D.M. Amorim 82 (MOSS).

Amplamente distribuída nas Américas tropical e subtropical (Barneby 1991). No Brasil, ocorre principalmente na Bahia e em Minas Gerais não havendo registro apenas para a flora do Rio Grande do Sul (BFG 2015).

Morfologicamente assemelhada às demais espécies de Mimosa encontradas na área de estudo. Entretanto, diferencia-se delas, principalmente, pelo fruto quadrangular com valvas contínuas. Encontrada florida e frutificada em maio.

Mimosa modesta Mart. var. ursinoides (Harms) Barneby, Brittonia 37: 153. $1985 . \quad$ Fig. 3h Material examinado: BRASIL. Rio Grande do Norte: Assú, Floresta Nacional de Assú, 03.V.2014, fl., L.D.M. Amorim 75 (MOSS).

Esta espécie é endêmica do Brasil, ocorrendo principalmente na Região Nordeste. Mimosa modesta var. ursinoides foi registrada para os Estados da Bahia, Pernambuco, Piauí, Rio Grande do Norte (BFG 2015), principalmente em áreas de Caatinga sobre solo arenoso, mas também no cerrado (Queiroz 2009).

Mimosa modesta caracteriza-se, principalmente, pela morfologia peculiar dos folíolos, assimetricamente orbiculares a ovais, ascendentes. Diferencia-se das demais representantes de Mimosa encontradas na área de estudo pelo hábito prostrado e ramos inermes. Encontrada florida em maio.

Mimosa sensitiva L., Sp. Pl.: 518. 1753. Fig. 3i Material examinado: BRASIL. Rio Grande do Norte: Assú, Floresta Nacional de Assú, 03.V.2014, fl. e fr., L.D.M. Amorim 80 (MOSS).

Mimosa sensitiva restringe-se à América do Sul (Barneby 1991). No nordeste brasileiro, ocorre nos Estados da Bahia, Ceará, Pernambuco, Maranhão e Piauí associada à Caatinga, Cerrado e Mata Atlântica (BFG 2015), sendo registrada pela primeira vez para o Rio Grande do Norte neste trabalho.

Pode ser facilmente reconhecível por apresentar 1 único par de pinas e dois pares de foliólulos por pina, sendo o folíolo interno do par proximal visivelmente menor que os demais. Encontrada florida e frutificada em maio.

Mimosa tenuiflora Benth., London J. Bot. 5: 92. 1846.

Fig. $3 \mathrm{j}$

Material examinado: BRASIL. Rio Grande do Norte: Assú, Floresta Nacional de Assú, 29.VI.2013, fl. e fr., L.D.M. Amorim 41 (MOSS).

Esta espécie é bastante comum no semiárido brasileiro, embora também ocorra em outros países latino-americanos (Dourado et al. 2013). Frequentemente associada a áreas de Caatinga arbustiva sobre solos arenosos (Queiroz 2009). 
Em campo pode ser facilmente reconhecida pela combinação do hábito arbustivo, ramos de casca enegrecida, aculeados, folhas pinadas com folíolos numerosos. Encontrada florida e frutificada em junho.

Neptunia plena (L.) Benth., J. Bot. (Hooker) 4: 355. 1841.

Fig. 3k

Material examinado: BRASIL. Rio Grande do Norte: Assú, Floresta Nacional de Assú, 22.II.2014, fl. e fr., L.D.M. Amorim 65 (MOSS).

Distribui-se pelo neotrópico, desde o Sul dos Estados Unidos até o Norte-Nordeste do Brasil, sendo também registrada para o CentroOeste (Córdula 2008; BFG 2015). De acordo com Córdula (2008), é uma espécie típica de litoral, mas no interior do Nordeste está frequentemente associada a corpos d'água. $\mathrm{Na}$ área de estudo, foi encontrada às margens da Lagoa do Piató.

A característica que prontamente a identifica e que, inclusive a distingue das demais Mimosoideae encontradas na área estudada, é a inflorescência heteromórfica, com flores estéreis e férteis, além da corola dialipétala. Encontrada florida e frutificada em fevereiro.

Piptadenia stipulacea (Benth.) Ducke, Arch. Jard. Bot. Rio de Janeiro 5: 126. 1930.

Material examinado: BRASIL. Rio Grande do Norte: Assú, Floresta Nacional de Assú, 29.VI.2013, fl. e fr., L.D.M. Amorim 45 (MOSS).

Esta espécie é endêmica da caatinga, ocorrendo exclusivamente no Nordeste brasileiro com exceção do Estado do Maranhão (BFG 2015), principalmente em áreas de Caatinga arbórea (Córdula 2008).

Piptadenia stipulacea também é uma das espécies que marcam a fisionomia da caatinga, sendo morfologicamente assemelhada à $M$. tenuiflora pela presença de acúleos de base larga nos ramos e pelo número elevado de folíolos por pina. Entretanto, a presença de nectário extrafloral, a casca acinzentada e a inflorescência amarela em P. stipulacea as diferenciam facilmente. Coletada florida e frutificada em junho.

Pityrocarpa moniliformis (Benth.) Luckow \& R.W.Jobson, Syst. Bot. 32(3): 573. 2007.

Fig. 31

Material examinado: BRASIL. Rio Grande do Norte: Assú, Floresta Nacional de Assú, 27.VII.2013, fl., L.D.M. Amorim 60 (MOSS).

Distribui-se nos Estados do Rio Grande do Norte, Paraíba, Piauí e Minas Gerais (BFG 2015), sendo comum em solos arenosos e de baixa fertilidade, ocorrendo menos frequentemente em tabuleiros litorâneos (Queiroz 2009).

Pityrocarpa moniliformis é uma espécie arbórea, de copa densa e inflorescência pêndula, características que a distingue de diversas outras espécies típicas da Caatinga. Compartilha inúmeras características com $P$. stipulacea, entretanto seus folíolos são maiores e o ovário encontra-se exserto da flor. A literatura indica a presença de nectário extrafloral, estrutura não observada no indivíduo coletado na área de estudo. Encontrada florida em julho.

\section{Chave para separação das espécies de Papilionoideae na FLONA de Assú}

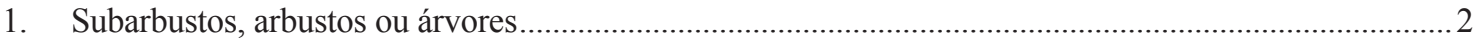

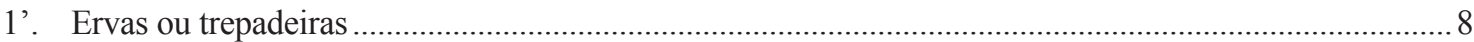

2. Flores sésseis ou curtamente pediceladas, com pedicelos de até $1,5 \mathrm{~mm}$ de comprimento.............. 3

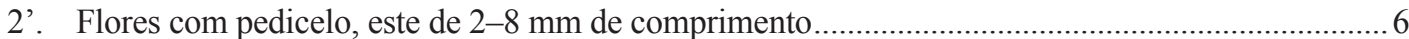

3. Inflorescência cacho ou panícula; flores brancas ou róseas; androceu diadelfo, anteras isomorfas

3'. Inflorescência espiga; flores amarelas; androceu monadelfo; anteras heteromorfas .................5

4. Ramos estriados a costados, com lenticelas punctiformes brancas; folíolos 9-13, alternos, sem distinção entre o terminal e os laterais de ápice obtuso a emarginado; inflorescência mais curta que a flor adjacente; cálice não laciniado; ovário não dilatado, longo estipitado Amburana cearensis

4'. Ramos não estriados, sem lenticelas; folíolos-7, opostos, o terminal visivelmente mais longo do que largo de ápice agudo; inflorescência mais longa que a folha adjacente; cálice 5-laciniado; ovário dilatado, séssil. Indigofera blanchetiana 
5. Estípulas bi-lanceoladas; folhas imparipinadas, sem pontuações glandulares; folíolos elípticos de ápices apiculados; cálice glabrescente Stylosanthes scabra

5'. Estípulas lanceoladas; folhas paripinadas, com numerosas pontuações glandulares; folíolos espatulados de ápices arredondados; cálice viloso Zornia brasiliensis

6. Folíolos opostos, venação camptódroma, bractéolas presentes; pedicelo 2-5 mm de comprimento; pétalas lilases ou roxas; estames 10; ovário séssil; estigma reduzido; fruto oblongo..... 7

6'. Folíolos alternos, venação eucamptódroma, bractéolas ausentes; pedicelo $8 \mathrm{~mm}$ de comprimento; pétalas brancas; estames 16-22; ovário estipitado; estigma dilatado; fruto largamente-elíptico ...

Trischidium molle

7. Estípulas subuladas, pecíolo pubescente, raque $4-9 \mathrm{~mm}$ de comprimento, estipelas presentes; folíolos oblongo-elípticos, de base arredondada; inflorescência axilar; bractéolas-2; cálice 4-laciniado; androceu heterodínamo, diadelfo; fruto com ápice apiculado

Galactia jussiaeana

7'. Estípulas estreito-triangulares, pecíolo glabrescente, raque $17-46 \mathrm{~mm}$ de comprimento, estipelas ausentes; folíolos espatulados a oblanceolados, de base cuneada; inflorescência terminal; bractéola-1; cálice 5-laciniado; androceu homodínamo, monadelfo; fruto com ápice falciforme Tephrosia purpurea

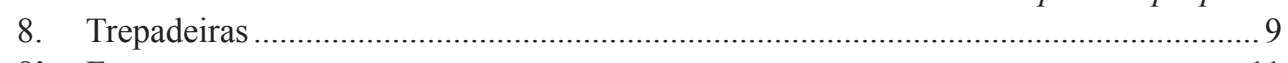

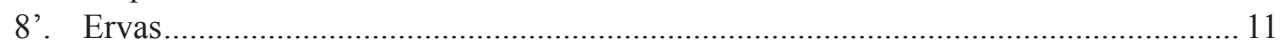

9. Pecíolo de 37-67 mm de comprimento; inflorescência mais longa que a folha adjacente; pedicelo ca. $1 \mathrm{~mm}$ de comprimento . 10

9'. Pecíolo de até $18,5 \mathrm{~mm}$ de comprimento; inflorescência mais curta que a folha adjacente; pedicelo 6-8 $\mathrm{mm}$ de comprimento. Centrosema brasilianum

10. Ramos seríceos; estipulas elípticas; ápice do estandarte profundamente emarginado; carena não torcida; androceu heterodínamo, monadelfo; ovário não dilatado; estigma estreitado; fruto com ápice apiculado

Canavalia brasiliensis

10'. Ramos glabrescentes; estípulas oblongo-deltóides; ápice do estandarte arredondado; carena fortemente torcida; androceu homodínamo, diadelfo; ovário dilatado; estigma dilatado; fruto com ápice falciforme.

Vigna peduncularis

11. Flor com cálice 4-laciniado 12

11'. Flor com cálice 5-laciniado 15

12. Ervas eretas; peciólulo glabrescente; tubo do cálice até $1,7 \mathrm{~mm}$ de comprimento; androceu com 5 estames férteis, heterodínamos; ovário glabro 13

12'. Ervas prostradas; peciólulo hirsuto a pubescente; tubo do cálice até $4 \mathrm{~mm}$ de comprimento; androceu com 10 estames férteis, homodínamos; ovário pubescente ou tomentoso. 14

13. Ramos glabros a glabrescentes; estípulas $4-7 \mathrm{~mm}$ de comprimento; folíolo de base obtusa, sendo o terminal igual aos laterais, venação camptódroma; lacínia central da bráctea terminando em folíolo; cálice glabrescente.

Stylosanthes humilis

13'. Ramos pubescentes com tricomas adesivos; estípulas de 12-14 mm de comprimento; folíolo de base aguda, sendo o terminal maior que os laterais, venação paralelódroma; lacínia central da bráctea não terminando em folíolo; cálice hirsuto

Stylosanthes angustifolia 
14. Estípulas não peltadas, 3,5-5 mm de comprimento; folhas imparipinadas; pecíolo hirsuto, 2,5-3,4 mm de comprimento; estipelas 3-4 mm de comprimento; folíolos 3-5, sem tricomas glandulares, venação reticulódroma; inflorescência racemosa mais curta que a flor adjacente, bráctea não peltada; flores violeta, ca. $27 \mathrm{~mm}$ de comprimento; androceu diadelfo, anteras isomórficas. Centrosema rotundifolium

14'. Estípulas peltadas, 13-14 mm de comprimento; folhas paripinadas; pecíolo glabrescente, 17-24 mm de comprimento; estipelas ausentes; folíolo-2, com pontuações glandulares, venação camptódroma; inflorescência espiga mais longa que a folha adjacente, bráctea peltada; flores amarelas, 7-9 $\mathrm{mm}$ de comprimento; androceu monadelfo, anteras heteromórficas Zornia gemella

15. Folíolos-3, de margem irregular; flor 13-20 mm de comprimento; lacínias do cálice menores que o tubo; ápice do estandarte emarginado; pistilo 11-18 mm de comprimento; estilete barbado na porção superior.

15'. Folíolos 6-10, de margem inteira; flor 3-7 mm de comprimento; lacínias do cálice iguais ou maiores que o tubo; ápice do estandarte arredondado; pistilo 5-8 $\mathrm{mm}$ de comprimento; estilete não barbado

16. Estípulas 2,5-4,5 $\mathrm{mm}$ de comprimento; pecíolo $20-48 \mathrm{~mm}$ de comprimento; folíolo de base obtusa; lacínias do cálice estreito-triangulares; flores vináceas ou violetas; estames ca. $14 \mathrm{~mm}$ de comprimento; pistilo 17-18 mm de comprimento; ovário seríceo. 17

16'. Estípulas 5-7 mm de comprimento; pecíolo 54-108 mm de comprimento; folíolo de base arredondada; lacínias do cálice subuladas; flores alaranjadas; estames 8-9 mm de comprimento; pistilo $11 \mathrm{~mm}$ de comprimento; ovário lanuginoso Macroptilium martii

17. Ramos costados; folíolo lobado com face adaxial velutina, o terminal maior que os laterais, venação actinódroma; flor $16 \mathrm{~mm}$ de comprimento; legume apiculado

Macroptilium atropurpureum

17'. Ramos estriados; folíolo irregularmente deltóide com face adaxial glabrescente, o terminal igual aos laterais, venação camptódroma; flor $20 \mathrm{~mm}$ de comprimento; legume não apiculado. Macroptilium lathyroides

18. Ramos estriados, estípulas deltóides a lanceoladas; pecíolo 8-10 mm de comprimento; folíolo de ápice acuminado, base assimétrica, alternos, os basais maiores que os distais; venação broquidódroma; bractéolas-2, ovais; pedicelo 6-11mm de comprimento; pétalas amarelas; androceu homodínamo, monadelfo; ovário estipitado; fruto lomento. Aeschynomene viscidula

18'. Ramos não estriados, estípulas subuladas; pecíolo 2-6,5 $\mathrm{mm}$ de comprimento; folíolo de ápice truncado ou retuso, base levemente atenuada, opostos, sem distinção entre basais e distais; venação hifódroma; bractéola-1, subulada; pedicelo $1 \mathrm{~mm}$ de comprimento; pétalas róseas; androceu heterodínamo, diadelfo; ovário séssil; fruto legume. Indigofera microcarpa

Aeschynomene viscidula Michx., Fl. Bor.-Amer. (Michaux) 2: 74. 1803. Fig. $4 \mathrm{~b}$ Material examinado: BRASIL. Rio Grande do Norte: Assú, Floresta Nacional de Assú, 22.II.2014, fl. e fr., L.D.M. Amorim 64 (MOSS; 03.V.2014, fl., L.D.M. Amorim 79 (MOSS).

No Brasil, distribui-se nos Estados do Mato Grosso do Sul, Alagoas, Bahia, Ceará, Pernambuco e Sergipe (BFG 2015) e está associada a solos arenosos e margens de rios temporários (Queiroz 2009). Neste trabalho, Aeschinomene viscidula é citada pela primeira vez para a o estado do Rio Grande do Norte.
Caracterizada por ser uma erva prostrada associada à presença de tricomas viscosos que tornam seus ramos pegajosos. Apresenta flores papilionóides amarelas, em tom mais claro ou escuro, e estandarte com arco basal avermelhado. Encontrada florida em fevereiro e maio e frutificada em fevereiro.

Amburana cearensis (Allemão) A.C.Sm., Trop. Woods 62: 30. 1940.

Fig. $4 \mathrm{a}$

Material examinado: BRASIL. Rio Grande do Norte: Assú, Floresta Nacional de Assú, 15. IV.2014, L.D.M. Amorim 69 (MOSS). 
Material adicional examinado: Brasil. Rio Grande do Norte: Assú, Floresta Nacional de Assú, 15.V.2012, fl., C.C.A. Costa 33 (MOSS).

Amburana cearensis ocorre em todo o Nordeste, mas também nas regiões Centro-Oeste e Sudeste do Brasil (BFG 2015). Distribuise predominantemente em áreas de Caatinga associada a diferentes tipos de solo, mas também no Cerrado, Mata Atlântica e na floresta pluvial em Minas Gerais (Almeida et al. 2010).

Esta espécie é a única dentre as Papilionoideae desse estudo que apresenta hábito arbóreo. Outra importante característica para o seu reconhecimento é a presença de uma única pétala e de ovário longamente estipitado, exserto do hipanto. Encontrada florida em maio.

Canavalia brasiliensis Mart. ex Benth., Commentat. Legum. Gen.: 71. 1837.

Fig. 4e

Material examinado: BRASIL. Rio Grande do Norte: Assú, Floresta Nacional de Assú, 20.IV.2013, fl., L.D.M. Amorim 19 (MOSS); 25.V.2013, fl. e fr., L.D.M. Amorim 22 (MOSS).

Canavalia brasiliensis possui distribuição neotropical. No Brasil, estende-se por quase todo o Nordeste, e em Estados das regiões Norte, Sudeste e Centro-Oeste (Córdula 2008). Caracteriza-se pelos folíolos largamente ovais e pelas flores róseas grandes e vistosas. Outra importante característica que a distingue das demais Papilionoideae desse trabalho, é a presença de cálice bilabiado, com um lábio tri-denteado. Encontrada florida em abril e maio e frutificada em maio.

Centrosema brasilianum (L.) Benth. var. angustifolium, Commentat. Legum. Gen.: 54. 1837.

Fig. 4c

Material examinado: BRASIL. Rio Grande do Norte: Assú, Floresta Nacional de Assú, 20.IV.2013, fl., L.D.M. Amorim 18 (MOSS).

Material adicional examinado: BRASIL. Rio Grande do Norte: Assú, Jusante do Rio Piranhas-Assú, 29.II.1993, fl. e fr., B. Gonçalves-Júnior. s.n. (MOSS 3745).

Espécie distribuída por quase todo o território brasileiro (BFG 2015), ocorrendo principalmente em ambientes antropizados, mas também às margens de rodovias (Queiroz 2009). Na FLONA foi encontrada à margem da trilha principal.

A variedade registrada na área de estudo caracteriza-se e diferencia-se de Centrosema brasilianum var. brasilianum pela forma dos folíolos, amplamente estreitados. Encontrada florida em abril.
Centrosema rotundifolium Mart. ex Benth., Commentat. Legum. Gen.: 55. $1837 . \quad$ Fig. 4d Material examinado: BRASIL. Rio Grande do Norte: Assú, Floresta Nacional de Assú, 03.V.2014, fl., L.D.M. Amorim 78 (MOSS).

Distribui-se por quase todo o Brasil, com exceção da região Sul (BFG 2015). Na Caatinga ocorre principalmente em áreas inundáveis sobre solo arenoso (Queiroz 2009). Na FLONA foi encontrada na trilha principal, onde é relativamente freqüente.

Diferencia-se de C. brasilianum principalmente por apresentar folhas com 3 ou 5 folíolos oblongoovais sendo o terminal menor que os laterais, além de ovário pubescente. Encontrada florida em maio.

Galactia jussiaeana Kunth, Nov. Gen. Sp. [H.B.K.] 6: 336.1823.

Material examinado: BRASIL. Rio Grande do Norte: Assú, Floresta Nacional de Assú, 06.V.2014, fl. e fr., L.D.M. Amorim 90 (MOSS).

Espécie nativa da América do Sul, onde se distribui amplamente (Burkart 1971). No Brasil, ocorre nas regiões Norte, Nordeste e CentroOeste (BFG 2015). Na Caatinga, distribui-se especialmente em áreas abertas sobre solo arenoso (Queiroz 2009). Galactia jussiaeana está sendo citada pela primeira vez para a flora potiguar neste trabalho.

Galactia jussiaeana compartilha inúmeras semelhanças com os representantes do gênero Macroptilium, dentre as quais a presença de folhas tri-folioladas e de ovário dilatado. Entretanto, pode ser reconhecida especialmente pelo cálice 4-laciniado e inflorescência mais curta que a folha adjacente. Encontrada florida e frutificada em maio.

Indigofera blanchetiana Benth., Fl. Bras. (Martius) 15(1): 40. 1859.

Material examinado: BRASIL. Rio Grande do Norte: Assú, Floresta Nacional de Assú, 27.VII.2013, fl. e fr., L.D.M. Amorim 58 (MOSS).

Indigofera blanchetiana é uma espécie endêmica do Brasil, restrita às regiões Sudeste e Nordeste (BFG 2015) e na Caatinga é comum em solos arenosos (Queiroz 2009). Na FLONA foi encontrada ao longo da trilha principal do local, sendo bastante comum.

Apresenta hábito subarbustivo, ereto, caracterizando-se ainda pelas flores papilionóides diminutas de tom rosado. Diferencia-se de $I$. microcarpa principalmente pelo hábito ereto. Encontrada florida e frutificada em julho. 
Indigofera microcarpa Desv., J. Bot. Agric. 3: 79. 1814.

Material examinado: BRASIL. Rio Grande do Norte: Assú, Floresta Nacional de Assú, 22.II.2014, fl. e fr., L.D.M. Amorim 66 (MOSS).

Esta espécie é amplamente distribuída pela América tropical e África (Córdula 2008). No Brasil, restringe-se às regiões Nordeste e Sudeste (BFG 2015) ocorrendo principalmente em áreas periodicamente alagadas sobre solo arenoso (Queiroz 2009). Na área de estudo foi encontrada às margens da Lagoa do Piató, onde é freqüente.

Caracteriza-se por ser uma erva prostrada com ramos cinéreos devido ao indumento seríceo presente nas estruturas vegetativas e reprodutivas. Distingue-se de I. blanchetiana, principalmente, pelo hábito além de apresentar folíolos e frutos menores e globosos. Encontrada florida e frutificada em fevereiro.

Macroptilium atropurpureum (L.) Urb., Symb. Antill. (Urban) 9(4): 457. $1928 . \quad$ Fig. 4h Material examinado: BRASIL. Rio Grande do Norte: Assú, Floresta Nacional de Assú, 20.IV.2013, f1., L.D.M. Amorim 18 (MOSS); 06.V.2014, fl. e fr., L.D.M. Amorim 88 (MOSS).

Apresenta distribuição pantropical e, no Brasil, ocorre em todas as regiões, mas no Nordeste está restrita à Bahia (BFG 2015) e ao Rio Grande do Norte (São-Mateus et al. 2013). $\mathrm{Na}$ área de estudo foi encontrada sobre solo arenoso na trilha principal da área.

Macroptilium atropurpureum diferencia-se das demais espécies congêneres registradas na área de estudo por apresentar folhas lobadas e flores violetas. Encontrada florida em abril e maio.

Macroptilium lathyroides (L.) Urb., Symb. Antill. (Urban). 9(4): 457. 1928.

Fig. $4 \mathrm{f}$

Material examinado: BRASIL. Rio Grande do Norte: Assú, Floresta Nacional de Assú, 27.VII.2013, fl. e fr., L.D.M. Amorim 51 (MOSS).

Ocorre em toda a América tropical (Maréchal et al. 1978). No Brasil, distribuise em quase todos os Estados (BFG 2015), estando associada à colonização de ambientes perturbados (Queiroz 2009).

Caracteriza-se pela presença de estrias nos ramos, folíolos indiferenciados, brácteas na extremidade distal da inflorescência e pelas flores vináceas. Encontrada florida e frutificada em julho.
Macroptilium martii (Benth.) Maréchal \& Baudet, Bull. Jard. Bot. Natl. Belg. 47: 257. 1977.

Fig. $4 \mathrm{~g}$

Material examinado: BRASIL. Rio Grande do Norte: Assú, Floresta Nacional de Assú, 25.V.2013, fl., L.D.M. Amorim 31 (MOSS); 27.VII.2013, fl. e fr., L.D.M. Amorim 49 (MOSS).

A espécie distribui-se por quase todo o território brasileiro estendendo-se até o Paraguai (Fevereiro 1988). Na Caatinga é comum em solos arenosos (Queiroz 2009). Na FLONA foi encontrada na trilha principal da área.

Macroptilium martii é facilmente reconhecível, principalmente, pelos ramos com tricomas longos e canescentes, vilosos, pelos folíolos suborbiculares a ovais e flores vináceas. Encontrada florida em maio e julho e frutificada em julho.

Stylosanthes angustifolia Vogel, Linnaea 13: 63. 1839.

Material examinado: BRASIL. Rio Grande do Norte: Assú, Floresta Nacional de Assú,03.V.2014, fl.,L.D.M. Amorim 77 (MOSS).

Distribui-se pelo norte da América do Sul, ocorrendo na Venezuela, Suriname e Guiana Francesa. No Brasil, está praticamente restrita às regiões Norte e Nordeste (Costa 2006). Na área de estudo foi coletada na trilha principal da área sobre solo arenoso.

A combinação dos folíolos lineares e inflorescências em espigas longas permitem o pronto reconhecimento de $S$. angustifolia e sua distinção das demais espécies de Stylosanthes registradas nesse estudo. Encontrada florida em maio.

Stylosanthes humilis Kunth, Nov. Gen. Sp. [H.B.K.] 6: 506. 1823.

Material examinado: BRASIL. Rio Grande do Norte: Assú, Floresta Nacional de Assú, 03.V.2014, fl., L.D.M. Amorim 72 (MOSS).

Possui distribuição neotropical e no Brasil não há registro para a região Sul (Costa 2006). $\mathrm{Na}$ Caatinga apresenta hábito herbáceo, anual, associada a ambientes antropizados (Queiroz 2009). Na área de estudo foi encontrada na trilha principal sobre solo arenoso. A espécie é citada pela primeira vez para a flora potiguar neste trabalho.

Diferentemente das espécies congêneres registradas na área de estudo, S. humilis apresenta inflorescência em espigas curtas e ramos mais 
ramificados. Os folíolos são estreitamente elípticos sem distinção entre o terminal e os laterais. Coletada florida em maio.

Stylosanthes scabra Vogel, Linnaea 12: 69-70. 1838.

Material examinado: BRASIL. Rio Grande do Norte: Assú, Floresta Nacional de Assú, 03.V.2014, fl., L.D.M. Amorim s.n. (MOSS).

Stylosanthes scabra pode ser diferenciada das demais espécies de Stylosanthes tratadas nesse trabalho por apresentar hábito subarbustivo, inflorescências do tipo espiga, curtas e capitadas. Encontrada florida em maio.

Esta espécie estende-se da Argentina ao Brasil, onde ocorre de Norte a Sul (Costa 2006). Em áreas de Caatinga é comum em matas pouco densas sobre solo arenoso (Queiroz 2009). Na área de estudo é freqüente, tendo sido encontrada ao longo da trilha principal.

Tephrosia purpurea (L.) Pers. subsp. purpurea, Blumea 28: 2. 1983.

Fig. $4 \mathrm{i}$

Material examinado: BRASIL. Rio Grande do Norte: Assú, Floresta Nacional de Assú, 06.IV.2013, fr., L.D.M. Amorim 15 (MOSS); 22.II.2014, fl. e fr., L.D.M. Amorim 67 (MOSS).

A espécie possui distribuição pantropical (Brummit 1968). No Brasil, ocorre em todo o Nordeste e em alguns Estados do Sudeste (BFG 2015). Na Caatinga surge como invasora em ambientes antropizados sobre solos arenosos (Queiroz 2009). Na área de estudo foi encontrada às margens da Lagoa do Piató, em solo argiloso.

O hábito subarbustivo e a presença de folíolos espatulados a oblanceolados mais largos próximos ao ápice são características que permitem o reconhecimento da subespécie purpurea, dentre os demais táxons congêneres registrados na caatinga. Encontrada florida em fevereiro e frutificada em fevereiro e abril.

Trischidium molle (Benth.) H.E.Ireland, Kew Bull. 62(2): 336. 2007.

Fig. $4 j$

Material examinado: BRASIL. Rio Grande do norte: Assú, Floresta Nacional de Assú, 15.III.2014, fr., L.D.M. Amorim 68 (MOSS).

Material adicional examinado: BRASIL. Rio Grande do Norte: Mossoró, Serra do Carmo, 11.X.1978, fl. e fr., O.F. Oliveira 618 (MOSS).

Trischidium molle é endêmica do Brasil e distribui-se pelas regiões Nordeste, Sudeste e CentroOeste (Ireland 2007) e na Caatinga é comum em solos arenosos (Queiroz 2009). Na área de estudo foi encontrada às margens da trilha principal.

Esta espécie pode ser reconhecida facilmente pela combinação do hábito arbustivo, folhas imparipinadas, com folíolos alternos, e pelos frutos elipsóides deiscentes. Segundo Queiroz (2009), tratase de uma planta cujos frutos permanecem na planta mesmo após a dispersão das sementes, característica observada durante a realização dos trabalhos de campo. Encontrada frutificada em março.

Vigna peduncularis (Kunth) Fawc. \& Rendle, Fl. Jamaica [Fawcett \& Rendle] 4: 68. 1920. Fig. 4k Material examinado: BRASIL. Rio Grande do Norte: Assú, Floresta Nacional de Assú, 27.VII.2013, fl. e fr., L.D.M. Amorim 55 (MOSS).

Distribui-se na América Central até o norte da Argentina (Maréchal et al. 1978; BFG 2015). No Brasil, ocorre em todas as regiões, e na Caatinga nordestina pode ser encontrada em florestas estacionais, matas ciliares ou ambientes antropizados (Queiroz 2009). Na área de estudo, foi registrada no interior da área em mata fechada. Neste trabalho é referida pela primeira vez para o Rio Grande do Norte.

Apresenta flores lilases, semelhantes às flores de C. brasiliensis apesar de menores que estas, caracterizando-se ainda pela carena torcida e frutos longos, lineares. Encontrada florida e frutificada em julho.

Zornia brasiliensis Vogel, Linnaea 12: 62. 1838.

Fig. 41

Material examinado: BRASIL. Rio Grande do Norte: Assú, Floresta Nacional de Assú, 25.V.2013, fl., L.D.M. Amorim 27 (MOSS); 27.VII.2013, fr., L.D.M. Amorim 50 (MOSS).

Ocorre na Venezuela (Mohlenbrock 1961) e no Brasil, onde está distribuída principalmente pela região Nordeste, mas também nas regiões Norte, Centro-Oeste e Sudeste (Perez 2009, BFG 2015). $\mathrm{Na}$ área de estudo é freqüente encontrada.

A espécie é facilmente reconhecida pela combinação do hábito subarbustivo, procumbente, pelas folhas 4-folioladas e bractéolas com pontuações glandulares, douradas. Encontrada florida em maio e julho e frutificada em julho.

Zornia gemella (Willd.) Vogel, Linnaea 12: 61 (-62). 1838.

Material examinado: BRASIL. Rio Grande do Norte: Assú, Floresta Nacional de Assú, 03.V.2014, fl. e fr., L.D.M. Amorim 70 (MOSS). 
A espécie possui distribuição neotropical (Mohlenbrock 1961). De acordo com BFG (2015), é sinônimo heterotípico de Zornia latifolia e, no Brasil, ocorre em quase todos os Estados. Segundo Queiroz (2009), na Caatinga, é encontrada como planta invasora, anual, em áreas perturbadas.

Zornia gemella pode ser reconhecida e diferenciada de $Z$. brasiliensis pela combinação do hábito herbáceo, ramos delgados e pelas folhas bi-folioladas não pontuadas, além das bractéolas elíptico-lanceoladas estas pontuadas. Encontrada florida e frutificada em maio.

\section{Agradecimentos}

A primeira Autora agradece ao Instituto Chico Mendes de Conservação da Biodiversidade (ICMBio) através do gestor da Floresta Nacional (FLONA) de Assú, a autorização para a realização dos trabalhos de campo. J. I. M. Melo agradece ao Conselho Nacional de Desenvolvimento Científico e Tecnológico (CNPq), a bolsa de Produtividade em Pesquisa (Proc. n. 302751/2012-2 - PQ-2).

\section{Referências}

Abílio, F.J.P. 2010. Bioma caatinga, ecologia, biodiversidade, educação ambiental e práticas pedagógicas. Editora Universitária da UFPB, João Pessoa. 196p.

Almeida, J.R.G.S.; Guimarães, A.G.; Siqueira, J.S.; Santos, M.R.V.; Lima, J.T.; Nunes, X.P. \& QuintansJúnior, L. J. 2010. Amburana cearensis - uma revisão química e farmacológica. Scientia Plena 6: 1-8.

APG III. 2009. An update of the Angiosperm Phylogeny Group classification for the orders and families of flowering plants. Botanical Journal of the Linnean Society 161: 105-121.

Barneby, C.R. 1991. Sensitivae Censitae: a description of the genus Mimosa Linnaeus (Mimosaceae) in the New World. Memoirs of the New York Botanical Garden 65:1-835.

Bentham, G. 1865. Leguminosae. In: Bentham, G. \& Hooker, J.D. (eds.). Genera Plantarum. Vol. 1, parte 2. Lovell Reeve \& Co., London. Pp. 434-600.

BFG. 2015. Growing knowledge: an overview of Seed Plant diversity in Brazil. Rodriguésia 66: 1085-1113.

Brasil - Ministério do Meio Ambiente. 2002. Agenda 21 Brasileira: resultado da consulta nacional. Disponível em <http:/www.mma.gov.br/estruturas/ agenda21/arquivos/resultcons.pdf $>$. Acesso em 9 dezembro 2013 .

Brasil - Ministério do Meio Ambiente. 2013. Bioma Caatinga. Disponível em <http://www.mma.gov. br/biomas/caatinga $>$. Acesso em 16 outubro 2013.
Bridson, D. \& Forman, L. 2004. The Herbarium Handbook. Royal Botanic Garden Kew, Kew. 334p.

Brummitt, R.K. 1968. New and little know species from the Flora Zambesiaca area: XX: Tephrosia. Boletim da Sociedade Broteriana 41: 219-393.

Burkart, A. 1971. El género Galactia (Leguminosae Phaseoleae) en Sudamérica con especial referencia a la Argentina y países vecinos. Darwiniana 16: 663-796.

Carvalho, P.E.R. 2007. Sabiá: Mimosa caesalpiniifolia. Circular Técnica 135. Disponível em <http:// www.cnpf.embrapa.br/publica/circtec/edicoes/ Circular135.pdf $>$. Acesso em 25 abril 2013.

Córdula, E. 2008. Distribuição e diversidade de leguminosas em áreas de caatinga no município de Mirandiba-PE. Dissertação de Mestrado. Universidade Federal de Pernambuco, Recife. 149p.

Costa, C.C.A. 2006. Produção de serrapilheira e entomofauna associada em área de caatinga na Floresta Nacional do Açú-RN. Dissertação de Mestrado. Universidade do Estado do Rio Grande do Norte, Mossoró. 177p.

Costa, N.M.S. 2006. Revisão do gênero Stylosanthes Sw. Tese de Doutorado. Universidade Técnica de Lisboa, Lisboa. 470p.

Dourado, D.A.O.; Conceição, A.S. \& Santos-Silva, J. 2013. O gênero Mimosa L. (Leguminosae: Mimosoideae) na APA Serra Branca/Raso da Catarina, Bahia, Brasil. Biota Neotropica 13: 1-17.

Fernandes, J.M. \& Garcia, F.C.P. 2008. Leguminosae em dois fragmentos de floresta estacional semidecidual em Araponga, Minas Gerais, Brasil: arbustos, subarbustos e trepadeiras. Rodriguésia 59: 525-546.

Fevereiro, V.P.B. 1988. Macroptilium (Benth.) Urban no Brasil (Leguminosae-Faboideae-PhaseoleaePhaseolinae). Arquivos do Jardim Botânico do Rio de Janeiro 28: 109-180.

Harris, J.G. \& Harris, M.W. 2001. Plant identification terminology: an illustrated glossary. $2^{\mathrm{a}}$ ed. Spring Lake Publishing, Utah. 260p.

Hickey, L.J. 1973.Classification of architecture of dicotyledonous leaves. American Journal of Botany 60: 17-33.

ICMBio - Instituto Chico Mendes de Conservação da Biodiversidade. 2013 Floresta Nacional de Açu, Assú-RN. Disponível em <http://www4.icmbio. gov.br/flonas/index.php?id_menu=112>. Acesso em 17 outubro 2013.

IDEMA - Instituto de Desenvolvimento Sustentável e Meio Ambiente do Rio Grande do Norte. 2013. Unidades Estaduais de Conservação Ambiental do RN, Natal-RN. Disponível em <http://www. idema.rn.gov.br/Conteudo.asp $>$. Acesso em 14 outubro 2013.

Ireland, H.E. 2007. Taxonomic changes in the South American genus Bocoa (Leguminosae - Swartzieae): 
reinstatement of the name Trischidium, and a synopsis of both genera. Kew Bulletin 62: 333-350.

Irwin, H.S. \& Barneby, R.C. 1982. The American Cassiinae. A synoptical revision of Leguminosae tribe Cassieae subtribe Cassiinae in the New World. Memoirs of the New York Botanical Garden 35: $1-918$.

Lavin, M.; Schrire, B.; Lewis, G.; Pennington, R.T.; Delgado-Salinas, A.; Thulin, M.; Hughes, C.; Beyra Matos, A. \& Wojciechowski, M.F. 2004. Metacommunity process rather than continental tectonic history better explains geographically structured phylogenies in legumes. Philosophical Transactions of the Royal Society 359: 1509-1522.

Lewis, G. P.; Schrire, B.; Mackinder, B. \& Lock, M. 2005. Legumes of the world. Royal Botanic Gardens, Kew. 592p.

Lira, R.B.; Maracajá, P.B.; Miranda, M.A.S.; Sousa, D.D.; Melo, S.B. \& Amorim, L.B. 2007. Estudo da composição florística arbóreo- arbustivo na Floresta Nacional de Açu no semi-árido do RN Brasil. ACSA - Agropecuária Científica no SemiÁrido 3: 23-30.

LPWG (The Legume Phylogeny Working Group). 2013. Legume phylogeny and classification in the $21^{\text {st }}$ century: Progress, prospects and lessons for other species-rich clades. Taxon 62: 217-248.

Maréchal, R.; Mascherpa, J. \& Stainier, F. 1978. Etudetaxonomique d'ungroupe complexe d'espèciesdesgenres Phaseolus et Vigna (Papilionaceae) surla base de doné es morphologiques et polliniques, traitéesparl'analyseinformatique. Boissiera 28: 1-273.

Miranda, M.A.S.; Maracajá, P.B.; Sousa, D.D.; Lira, R.B.; Melo, S.B. \& Amorim, L.B. 2007. A flora herbácea na FLONA de Açú - RN. ACSA Agropecuária Científica no Semi-Árido 3: 31-43.

Mohlenbrock, R.H. 1961. A monograph of the Leguminous genus Zornia. Webbia: Journal of Plant Taxonomy and Geography 16: 1-141.

Payne, W.W. 1978. A glossary of plant hair terminology. Brittonia 30: 239-255.

Perez, A.P.F. 2009. O gênero Zornia J.F.Gmel (Leguminosae, Papilionoideae, Dalbergieae):
Revisão taxonômica das espécies ocorrentes no Brasil e filogenia. Tese de Doutorado. Universidade Estadual de Campinas, Campinas. 415p.

Polhill, R.M.; Raven, P.H. \& Stirton, C.H. 1981. Evolution and systematics of the Leguminosae. In: Polhill, R.M. \& Raven, P.H. (eds.). Advances in Legume Systematics. Royal Botanic Gardens, Kew 1: 1-26.

Queiroz, L.P. 2009. Leguminosas da Caatinga. Universidade Estadual de Feira de Santana, Feira de Santana. 467p.

Queiroz, R.T. \& Loiola, M.I.B. 2009. O gênero Chamaecrista Moench (Caesalpinioideae) em áreas do entorno do Parque Estadual das Dunas de Natal, Rio Grande do Norte, Brasil. Hoehnea 36: 725-736.

Radford, A.E.; Dickison, W.C.; Massey, J.R. \& Bell, C.R. 1974.Vascular Plant Systematics. Harper Collins, New York. 891p.

Rizzini, C.T. 1977. Sistematização terminológica da folha. Rodriguésia 29: 103-125.

Santos, E.A.L. \& Jerônimo, C.E.M. 2013. Unidades de Conservação da natureza: diagnóstico do programa estadual de Unidades de Conservação-PEUC no Rio Grande do Norte-Brasil. Monografias ambientais REMOA/UFSM 11: 2435-2445.

São-Mateus, W.M.B.; Cardoso, D.; Jardim, J.G. \& Queiroz, L.P. 2013. Papilionoideae (Leguminosae) na Mata Atlântica do Rio Grande do Norte, Brasil. Biota Neotropica 13: 315-362.

Secretaria Municipal de Desenvolvimento e Meio Ambiente de Assú. 2001. Projeto Elaboração da Agenda 21 local. Disponível em <http://www. google.com.br/url/dmg>. Acesso em 17 outubro 2013.

Vaz, A.M.S.F. \& Tozzi, A.M.G.A. 2003. Sinopse de Bauhinia sect. Pauletia (Cav.) DC. (Leguminosae: Caesalpinioideae: Cercideae) no Brasil. Revista Brasileira de Botânica 28: 477-491.

Weber, C.R.; Soares, C.M.L.; Lopes, A.B.D.; Silva, T.S.; Nascimento, M.S. \& Ximenes, E.C.P.A. 2011. Anadenanthera colubrina: um estudo do potencial terapêutico. Revista Brasileira de Farmácia 92: 235-244. 
